\title{
EDUCAÇÃO AMBIENTAL: UM ESTUDO DE CASO A PARTIR DA COMPREENSÃO DOS PROFESSORES DO ENSINO FUNDAMENTAL II
}

\author{
Lilian Pittol Firme de Oliveira ${ }^{1}$ \\ Roseli Barreto da Silva ${ }^{2}$
}

\begin{abstract}
Resumo: Há mais de três décadas o tema sustentabilidade e o termo Educação Ambiental (EA) tem surgido em publicações, tanto no âmbito de órgãos públicos quanto no cenário privado. Porém, percebe-se que poucos avanços chegaram a ocorrer de fato para tornar a sociedade atual mais sustentável. Este artigo visa compreender de que maneira a EA é abordada pelos professores no processo de ensino em um município no sul do Estado do Espírito Santo. Objetivando verificar a compreensão do professor na dimensão social, econômica, humana e cultural neste tema, foram abordados como sujeitos desta pesquisa os professores e os estudantes do Ensino Fundamental II. Buscou-se um panorama sobre até que ponto a EA está sendo compreendida no âmbito escolar.
\end{abstract}

Palavras-chave: Educação Ambiental; Meio Ambiente; Preservação Ambiental; Consciência Ambiental.

Abstract: For more than three decades the theme sustainability and the term Environmental Education (EE) has appeared in publications, both within the scope of public agencies as well as in the private scenario. However it is perceived that few progresses has actually occurred to make today's society more sustainable. This article aims to understand how EE is approached by teachers in the teaching process on a municipality in the south of the state of Espírito Santo. Aiming to verify the teacher understanding of the social, economic, human and cultural dimension in this theme, teachers and students of Elementary School II were approached as subjects of this research. Was sought an overview of how far the EE is being understood in the school context.

Keywords: Environmental Education; Environment; Environmental Preservation; Environmental Awareness.

${ }^{1}$ Doutora em Engenharia Ambiental e professora do Programa de Mestrado da Faculdade de Cricaré, São Mateus (ES). E-mail: Ipfirme@gmail.com.

Link para o Lattes: http://lattes.cnpq.br/5048256470280700.

${ }^{2}$ Mestre em Ciências, Tecnologia e Educação pela Faculdade Vale do Cricaré, São Mateus (ES). E-mail: barretodasilvaroseli@yahoo.com.br Link para o Lattes: http://lattes.cnpq.br/7053030291728148. 


\section{Introdução}

Desde os primórdios da humanidade, havia uma unicidade orgânica entre o homem e a natureza, onde o ritmo de trabalho e de suas vidas associava-se ao ritmo da natureza. No contexto do modo de produção capitalista, este vínculo se rompeu, pois, a natureza, que antes era um meio de subsistência para o homem, veio a integrar o conjunto dos meios de produção nos quais começou a ser explorada a matéria-prima retirada do meio ambiente, em que o explorador - o homem - passou a beneficiar-se financeiramente.

Observa-se que nas últimas décadas vêm se intensificando as preocupações em relação ao meio ambiente e diversos setores da sociedade têm desenvolvido atividades, projetos e conscientização. Isso ocorre no intuito de envolver as comunidades e a sociedade, procurando sensibilizá-las para as questões ambientais e mobilizá-las para a mudança de hábitos e de posturas benéficas para a preservação ambiental.

Entretanto, também se percebe que a sociedade atual vive um período de problemas ambientais, acidentes naturais ou situações provocadas pelo homem e pelo consumismo. De acordo com Leff (2009, p. 42): " $A$ crise ambiental do nosso tempo é o sinal de uma nova história”. Essa visão vai de encontro ao que o homem - enquanto indivíduo que interage com o meio ambiente constantemente - faz e interfere, com as atitudes e as decisões que toma escrevendo a cada momento a história do planeta.

Neste contexto, surge a necessidade de a EA ser abordada no sistema educativo e esta tende a questionar e a transformar a educação, como um todo, trazendo fundamentos claros e processos metodológicos eficazes. No entanto, o que é possível perceber na prática é que as publicações acadêmicas sobre EA raramente chegam às escolas.

A EA no discurso dos processos sociais nasce da sensibilidade de aliar conhecimento científico, tecnológico, artístico e cultural com uma nova consciência de respeito aos seres humanos e aos recursos naturais, bem como perspectivas de formar consciência ambiental por meio da difusão de novos valores, o que acaba resultando numa dimensão culturalmente consciente de atitudes ecológicas.

Sendo assim, nota-se que o processo educativo deve ser planejado e vivenciado no sentido de possibilitar aos indivíduos, a compreensão, a sensibilização e, especialmente ações que resultem em formar uma conscientização equilibrada quando o assunto for preservação ambiental. Isto é, percebe-se que a escola naturalmente já tem um ambiente propício para iniciar, ensinar, estimular e propagar a Educação Ambiental.

Nesse sentido, Reigota (2009) discorre que a problemática ambiental não pode ser reduzida só aos aspectos geográficos e biológicos de um lado, ou só aos aspectos econômicos e sociais de outro. Nenhum deles, isolado, possibilitará o aprofundamento do conhecimento sobre essa problemática. Para se tomar decisões adequadas na direção do crescimento cultural, da melhoria 
da qualidade de vida e da preservação ambiental, antes de tudo, se faz necessário refletir sobre como devem ser as relações socioeconômicas e ambientais.

Segundo enfatiza o autor "a Educação Ambiental tem uma história quase oficial, que a relaciona com conferências mundiais e com os movimentos sociais em todo mundo" (REIGOTA, 2009, p. 21). Em 1968, por exemplo, foi realizada em Roma uma reunião com um pequeno grupo de empresários, diplomatas, cientistas, educadores, economistas e funcionários governamentais, um grupo de 30 profissionais. Na ocasião discutiram sobre o uso indiscriminado dos recursos naturais. Hoje essa reunião é conhecida como o Clube de Roma, que é uma Organização Não Governamental (ONG).

Posteriormente, no Brasil, os autores Veiga, Amorim e Blanco (2005) descreveram as informações de que o Censo Escolar de 2001 foi o primeiro a incluir uma questão sobre a EA, e constatou que $61,2 \%$ de todas as escolas brasileiras declararam trabalhar com esta temática, e, mais tarde, no ano de 2004, este percentual saltou para $94 \%$.

Os resultados desses dois censos mostram que, atualmente, a EA está presente em muitas escolas. Além disso, o estudo intitulado "O que fazem as escolas que dizem que fazem Educação Ambiental?" produzido por Trajber e Mendonça, em 2006, Instituto Nacional de Estudos e Pesquisas Educacionais Anísio Teixeira (Inep), do Ministério da Educação (MEC), em escolas de Ensino Fundamental e Médio de todo o país, também identificou dados importantes sobre isso.

Foi assim que surgiu, então, a necessidade de se investigar como a EA vem sendo aplicada, averiguando-se os projetos ou programas em uma escola da rede pública localizada no sul do Espírito Santo.

Percebe-se que no momento histórico atual, o meio ambiente constituise em ponto de convergência, canalizando um grande investimento políticoideológico para a sociedade dita democrática. A escola, por exemplo, é solicitada a trabalhar com o meio ambiente não só como um tema entre outros, mas como tema de destaque, que deve ser abordado ao longo de toda a formação dos alunos. $E$, isso deve ocorrer de forma corrente: a inclusão da questão ambiental é requisitada, é esperada, e é também capaz de produzir um sentido de atualidade para o programa pedagógico, funcionando como elemento de prestígio para os pais-clientes.

Reigota (2009) descreve que os meios de comunicação de massa exercem uma função educativa fundamental, pois os mesmos têm o poder de alcançar todas as classes sociais e, atualmente, com a facilidade da internet, conseguem atingir especialmente os mais jovens. Assim, a divulgação de problemas ambientais, dos impactos deles na sociedade e das atitudes individuais ou em grupo podem ser adotadas para melhorar a qualidade de vida têm condições de serem divulgadas com mais frequência estimuladas pela Educação Ambiental. 
Entende-se que o objetivo da escola não é mudar pensamentos, mas partilhar ações e projetos que busquem melhorar o entendimento do que acontece ao redor do indivíduo, tanto no mundo quanto no entorno da comunidade em que vive.

A pesquisa justifica-se pelo fato de que uma das medidas para a inclusão da questão ambiental nos programas escolares é por meio dos professores, já que juntamente com os pais são formadores de opinião, transmissores de saberes e de novas tendências. O professor, ao capacitar-se na área ambiental, poderá desenvolver projetos educacionais interdisciplinares formando cidadãos conscientes e empenhados em desenvolver novas estratégias para a preservação do meio ambiente.

Acredita-se que a EA deve ser incrementada na formação do professor e os profissionais que já estão formados há algum tempo poderão adquirir esse conhecimento por intermédio de práticas, de projetos em parceria com órgãos governamentais e não governamentais. Logo, a prática desse assunto é uma medida importante para a inserção do tema na formação e na didática dos professores.

\section{A Educação Ambiental}

Sabe-se que o atual momento histórico da Educação Ambiental (EA) é decisivo e influencia no comportamento dos diversos setores. É possível observar, por conseguinte, que a implantação da mesma, realizada de forma eficaz, se faz na fase inicial do aprendizado escolar, época na qual se procura moldar indivíduos formadores de opinião.

Deve-se considerar que, segundo Reigota (2009, p. 33) afirma: "é ainda comum observarmos afirmações de que Educação Ambiental é o mesmo que ensino da ecologia". Pode-se arriscar, portanto, em incluir nesta observação as disciplinas de Geografia e Ciências. Neste sentido, vê-se a importância da interdisciplinaridade, bem como é possível esclarecer que cada uma dessas disciplinas tem a própria grade curricular, mas compreende-se que todas podem abordar o tema meio ambiente.

De acordo com o pensamento de Leff (2009, p. 18) "a crise ambiental é uma crise da razão, do pensamento, do conhecimento". O educador ainda se refere aos problemas ambientais como complexos, pois acredita que eles levam a uma nova visão, quando articula que

A complexidade ambiental não apenas leva a necessidade de aprender fatos novos (mais complexos), mas também inaugura uma nova pedagogia, que implica reapropriação de conhecimento desde o ser o mundo e de ser no mundo, a partir do saber e da identidade que forjam e se incorporam ao ser de cada indivíduo e cada cultura [...] (LEFF, 2009, p. 20, grifo do autor). 
O homem é o único ser capaz de traçar seu próprio destino. Diante disso, Reigota (2009, p. 16) escreve o seguinte: "[...] Dificilmente se considera um elemento da natureza, mas um ser a parte, como um observador $e$ explorador dela". Este pensamento vem de encontro ao mau comportamento do ser humano em relação ao meio ambiente, em que o papel do mesmo é somente de explorador.

Os conceitos de EA encontrados na bibliografia levantada durante esta pesquisa revelam pontos bastante comuns, como podem ser vistos em alguns exemplos citados a seguir. Guimarães (2007, p. 14), por exemplo, diz que a

Educação Ambiental apresenta-se como uma dimensão do processo educativo, voltada para a participação de seus atores, educandos e educadores, na construção de um novo paradigma que contemple as aspirações populares de melhor qualidade de vida sócio econômica e um mundo ambientalmente sadio.

Já o Art. 10 da Lei $n^{\circ}$ 9.795, de 27 de abril de 1999, entende por EA os processos pelos quais tanto o indivíduo quanto a coletividade "constroem valores sociais, conhecimentos, habilidades, atitudes e competências voltadas para a conservação do meio ambiente, bem de uso comum do povo, essencial a sadia qualidade de vida e sua sustentabilidade" (BRASIL, 1999).

Entende-se, por intermédio da visão de alguns autores, que se deve expor a EA de forma conscientizadora, em que o discente possa refletir sobre a própria responsabilidade com o meio ambiente e se conscientizar de que ele como indivíduo também é parte do meio ambiente. Com isso, o comportamento em relação ao mesmo tem relação direta com o cotidiano dele.

\section{Educação Ambiental no Brasil e no mundo}

O mundo viveu na década de 1960 uma queda da qualidade de vida, devido à degradação ambiental. Um processo que modificou a fauna, a flora $\mathrm{e}$ a biodiversidade, já que acontecia um desequilíbrio ambiental. Encontram-se na mídia e na citação de autores os registros de que houve, no ano de 1962, o lançamento do livro "Primavera Silenciosa", de Rachel Carson. O livro representou um marco para o movimento ambientalista internacional, pois já neste momento se combatia os CFCs, a questão das emissões de CO2 (dióxido de carbônico) e o aquecimento global.

$\mathrm{Na}$ descrição de Dias (1992), é válido lembrar que no Brasil, depois que foi promulgada a Constituição Federal de 1988 - a primeira constituição nacional a mencionar e abordar de fato a temática do meio ambiente -, foi possível perceber uma evolução da legislação ambiental brasileira como um 
expressivo aperfeiçoamento, em que houve a edição de diversas leis de extrema relevância (DIAS, 1992).

Algumas dessas leis se destacaram nos anos seguintes. É possível conferir quais são elas no Quadro 1, a seguir.

\begin{tabular}{|c|c|c|}
\hline Nome Popular & Lei & $\begin{array}{l}\text { Data de } \\
\text { criação }\end{array}$ \\
\hline Lei de Biossegurança & no 11.105 & 02/03/1995 \\
\hline Lei de Política Nacional de Recursos Hídricos & $\mathrm{n}^{\circ} 9.433$ & $08 / 01 / 1997$ \\
\hline Lei de Crimes Ambientais & $\mathrm{n} \div 9.605$ & $12 / 02 / 1998$ \\
\hline Lei da Política Nacional de Educação Ambiental & $\mathrm{n} \times 9.795$ & $27 / 04 / 1999$ \\
\hline Lei do Sistema Nacional de Unidades de Conservação & $\mathrm{n} 09.985$ & $18 / 07 / 2000$ \\
\hline $\begin{array}{l}\text { Lei sobre Poluição Causada pelo Lançamento de óleo e } \\
\text { outras Substâncias Nocivas em Águas Nacionais }\end{array}$ & $n^{0} 9.966$ & $28 / 04 / 2000$ \\
\hline $\begin{array}{l}\text { Lei de Diretrizes Gerais da Política Urbana Nacionalizou } \\
\text { Estatuto da Cidade }\end{array}$ & $\mathrm{n}^{0} 10.257$ & $10 / 07 / 2001$ \\
\hline Normas de Proteção e Acesso aos Recursos Genéricos & no 13.123 & $20 / 05 / 2001$ \\
\hline Lei de Acesso a Informações Ambientais & no 10.650 & $16 / 04 / 2003$ \\
\hline
\end{tabular}

Fonte: Autoria própria.

A Constituição Federal Brasileira (1988, p. 103) tem capítulo direcionado para o meio ambiente em seu Art. 225. Neste está disposto que: "Todos têm direito ao meio ambiente ecologicamente equilibrado, bem de uso comum do povo e essencial à sadia qualidade de vida, impondo-se ao poder público e à coletividade o dever de defendê-lo e preservá-lo para as presentes e futuras gerações".

Nota-se que as atividades econômicas não devem ser separadas das questões ambientais. Os danos ambientais afetam a humanidade de diversas maneiras (sejam elas a erosão dos solos, o desmatamento, a poluição, a contaminação dos recursos hídricos) e em diferentes formas e intensidade. Os indivíduos devem perceber as suas próprias responsabilidades e necessidades, e buscar soluções para os problemas ambientais de modo contínuo.

É válido ressaltar, então, que a EA no âmbito escolar precisa ser entendida não como uma simples passagem de informações, mas também como um instrumento que venha proporcionar, acima de tudo, mudanças comportamentais em todos os envolvidos no processo educacional em relação aos problemas ambientais. Com isso, pode-se promover reflexos positivos transformadores e integradores das relações entre a sociedade e o meio ambiente, possibilitando, assim, uma melhoria na qualidade de vida de toda a população.

Atualmente, tornou-se perceptível que a EA se faz necessária nos mais diversos segmentos. Com tantos problemas que estão acontecendo devido à má atitude do ser humano por um lado, por outro observam-se também 
algumas mudanças de pensamento e de atitudes de uma parcela da sociedade em muitos países e inúmeras comunidades.

Essas mudanças podem ser vistas, por exemplo, em algumas atividades que vão desde o cenário das famílias que escolhem ter uma vida mais minimalista até o universo corporativo, em que empresas e ONGS estão trabalhando, diariamente, por um objetivo comum: ver um mundo melhor, menos poluído e com mais qualidade de vida e de recursos disponíveis para as próximas gerações.

Evidencia-se, então, que é preciso que a população, especialmente na infância possa obter conhecimento sobre esses fatos. Assim, espera-se que ao aprender desde cedo como preveni-los e a disseminar essas informações, as crianças poderão crescer com uma mentalidade mais sustentável e terão condições de repassar esse conhecimento. Dessa forma, possivelmente se tornarão multiplicadores da EA.

Tem-se conhecimento de que a interação entre o homem e a natureza se faz de forma simultânea e natural, mesmo que ele - o ser humano - não constate este fato. Nesse sentido, é possível notar que se faz urgente que, enquanto um ser pensante, com capacidade de discernimento, o homem transforme as próprias atitudes em respeito à diversidade e à sustentabilidade.

\section{A Educação Ambiental no âmbito escolar}

É claro e notório que a educação é a base para o desenvolvimento de um país. Pode até parecer lugar comum, quando se depara com esse tipo de afirmação, mas é por intermédio da educação que as pessoas passam a ter subsídios para exigir seus direitos e ter consciência de que é preciso cumprir seus deveres. Isto é, todos têm condições de desempenhar o seu próprio papel de cidadãos ambientais e na proposta de se conviver em sociedade.

Em virtude disso, está a importância de não acontecerem somente ações pontuais, mas que possam transcender o ambiente escolar, alcançando as comunidades nas quais residam estudantes, professores, funcionários, buscando modificações de atitudes, valores, provocando uma reflexão que desperte toda a sociedade, visando à sensibilização e à mudança de postura quanto às questões ambientais (STEIN; DOROW, 2011).

Percebe-se, então, o papel fundamental que cabe à escola, no campo do ambiente humano, é o de promover condições necessárias para a melhoria da qualidade de vida de todos os envolvidos no processo. Isso ocorre como alerta para o real problema da finitude dos recursos naturais, do consumo exagerado, da crescente geração de lixo, da escassez e contaminação das águas e outros mais.

Assim, tornou-se fundamental que as escolas possuam projetos de EA com ações concretas voltadas para a preservação do meio ambiente e que 
estejam inseridas no dia a dia dos estudantes, a fim de possibilitar ao educando a construção de conhecimentos, e postura em relação ao tema.

Diante desse cenário, é possível constatar que só a realização de projetos impostos por pequenos grupos ou atividades isoladas, que são gerenciadas por apenas alguns indivíduos da comunidade escolar - como um projeto de coleta seletiva (no qual a participação dos alunos se resume em depositar o lixo em latões determinados por cores diferentes) -, por exemplo, não é a solução. Afinal, esses projetos não serão capazes de produzir a mudança de mentalidade necessária para que a atitude de reduzir o consumo, reutilizar e reciclar resíduos sólidos se estabeleça e transcenda, assim, para além do ambiente escolar, entendendo-se pelas casas, pelas ruas, pelos bairros. Enfim, alcançando toda a comunidade envolvida.

Freire (1987) em seus escritos discorre que a educação, nos moldes como está organizada, não ajuda a formar, mas sim, apenas informa aos cidadãos. $\mathrm{E}$, dessa forma, cria-se um enorme abismo entre as classes que dominam e as dominadas.

A Agenda 21 Escolar (1992), por exemplo, se coloca como instrumento de planejamento para aplicação do meio de influência da escola, tanto nos recintos escolares, quanto no meio familiar e social em que tal influência é exercida.

Vale observar que a Agenda 21 Global foi construída durante dois anos. Cada país tem a própria Agenda 21, em que o compromisso com a sustentabilidade deve ser o foco. Logo, percebe-se: para que ela tenha sucesso é necessário haver o engajamento de toda sociedade, pois a Agenda 21 é responsável por buscar causas de problemas bem como possíveis soluções com o desenvolvimento sustentável.

\section{Histórico e objetivo da Educação Ambiental}

Atualmente, tornou-se fundamental que as escolas possuam projetos de EA com ações concretas voltadas para a preservação do meio ambiente e que estejam inseridas no dia a dia dos estudantes, a fim de possibilitar ao educando a construção de conhecimentos e postura em relação ao tema.

Segundo descreve a professora e pesquisadora Tristão (2016, acesso em 10 ago. 2019), que é coordenadora do Núcleo Interdisciplinar de Pesquisa e Estudo em Educação Ambiental (NIPEEA) da Universidade Federal do Espírito Santo (UFES), "a escola é o meio ambiente".

Portanto, é possível acreditar que a Educação Ambiental seja um processo pelo qual o indivíduo aprenda como funciona o ambiente, como os seres humanos dependem dele, como o afetam e como é plausível promover a sustentabilidade. 


\section{Educação Ambiental na realidade das salas de aula}

Como condição imprescindível para uma EA efetiva, se faz necessário refletir e exercitar, em todas as práticas educativas, as relações individuais e coletivas entre seres humanos o meio ambiente como um todo. Logo, as escolas se destacam como espaços privilegiados para a implementação de atividades que propiciem tal reflexão.

Observa-se que é indispensável também considerar os conhecimentos, dos indivíduos envolvidos, tendo em vista a especificidade do contexto cultural em que os mesmos estão inseridos. Procura-se nos Parâmetros Curriculares Nacionais (PCNs) mostrar que a interdisciplinaridade é de fundamental importância para a Educação Ambiental.

Neste sentido, portanto, pode-se concluir que tanto a capacitação do professor quanto a disponibilidade e o acesso ao material didático adequado e necessário nas escolas são de extrema importância.

Sabe-se que a educação básica em seus diferentes níveis e modalidades, assim como a educação superior, deve adotar conteúdos concernentes ao meio ambiente e à formação de hábitos e atitudes que preservem tanto a qualidade de vida quanto os recursos naturais do país e do planeta. A Constituição Federal (1988) estabelece no inciso VI do § 1 de seu art. 225, como competência do poder público, "promover a Educação Ambiental em todos os níveis de ensino e a conscientização pública para a preservação do meio ambiente".

Nota-se, que mesmo sendo um tema fundamental e que é necessário ser extensa e profundamente debatido e trabalhado desde as salas de aulas até as empresas e, embora esteja em evidência, agora mais do que nunca especialmente em virtude das queimadas na Amazônia e dos últimos acontecimentos que foram registrados antes e durante a pandemia de Covid-19 nos últimos meses -, a conservação ambiental ainda não é um consenso na sociedade.

De tal modo, é válido pensar e visualizar que há a necessidade de aplicar estratégias pedagógicas para cada região, já que se observa uma particularidade em cada uma. Ou seja, as estratégias utilizadas em grandes centros urbanos, por exemplo, não necessariamente podem ser as mesmas aplicadas em escolas de área rural, tendo em vista que se tratam de realidades complexas e diferentes. Logo, os resultados também não seriam os mesmos.

Além disso, é preciso levar em consideração o andamento dos programas ambientais existentes, em sua continuidade (já que a cada eleição tanto os governantes quanto as equipes de trabalho podem mudar). É notório que, por vezes, eles podem ser prejudicados pelo fator da descontinuidade administrativa do governo.

Trata-se de uma pesquisa que permitiu observar de perto a importância de uma instituição de ensino, especialmente da rede pública, que busca 
trabalhar focada em ampliar o ensino da EA e a relevância de ter objetivos do Ensino Fundamental, como "utilizar as diferentes linguagens (verbal, matemática, gráfica, plástica e corporal) como meio para produzir, expressar e comunicar suas ideias [...]" (PPP, 2019, p. 7).

Por meio da pesquisa compreendeu-se que a escola procura, por meio de atividades extras como o reforço escolar, ampliar o período de permanência do aluno na unidade educacional tornando possíveis novas oportunidades de aprendizagem. E, com isso, tem obtido resultados favoráveis como, por exemplo, evitar a evasão escolar e reduzir ou até eliminar os casos de repetência do ano letivo. Neste contexto pode-se explorar a aprendizagem de forma lúdica.

\section{Abordagem interdisciplinar na Educação Ambiental}

A interdisciplinaridade reúne aspectos que ficaram isolados uns dos outros pelo tratamento disciplinar. Segundo Hammes (2012) a EA, por ser um tema transversal, "pode ser inserida no contexto de todas as disciplinas e séries do Ensino Fundamental e Médio, de tal modo que o equilíbrio dinâmico da natureza seja fonte de inspiração na busca de alternativas de ação". Isto é, a interdisciplinaridade permite que sejam aproveitados os conteúdos de cada disciplina de forma que elas possam se complementar.

Portanto, vê-se que a interdisciplinaridade requer um trabalho de capacitação do professor. Sobre o assunto, alguns educadores, autores e pesquisadores citam que a interdisciplinaridade é um ciclo de cooperação e diálogo entre as disciplinas. Dias (2003, p. 117) discorre sobre o meio ambiente que as "múltiplas interações de fundo ecológico, político, econômico e étnico cultural, científico e tecnológico, não se poderia tratar o assunto em uma única disciplina.

Observa-se a importância da interdisciplinaridade quando há necessidade de mostrar ao discente o papel dele no meio ambiente, fazer com que conheça o tema sob várias óticas, principalmente a de que esse assunto faz parte do dia a dia do mesmo. Assim podemos argumentar que a EA é dinâmica, recíproca entre as disciplinas. É o complemento de cada uma delas no campo tecnológico, científico, e está presente no cotidiano.

\section{A importância da interdisciplinaridade de acordo com os PCNs}

De acordo com o discurso da Unesco (2005, p. 44), a EA "é uma disciplina bem estabelecida que enfatiza a relação dos homens com 0 ambiente natural, as formas de conservá-lo, preservá-lo e de administrar seus recursos adequadamente". Neste discurso percebe-se a importância da EA, em que cada disciplina colabora para a inserção da mesma nos projetos escolares, dada a diversidade do tema meio ambiente.

Tem-se na Lei de Diretrizes e Bases da Educação (Lei n 9394, criada em 1996), a descrição de que a EA deverá ser considerada na concepção dos 
conteúdos curriculares de todos os níveis de ensino, sem constituir disciplina específica, implicando no desenvolvimento de hábitos e atitudes sadias de conservação ambiental e respeito à natureza.

Percebe-se que as atividades educativas praticadas isoladamente não atingem os objetivos maiores da EA se dissociadas de um processo de planejamento contínuo de construção de conhecimentos. Com isso, é necessário criar estratégias que permitam mobilizar a comunidade escolar acerca do tema, agregando os aspectos que envolvem a teoria da educação a outras questões que atingem a sociedade.

Desta forma, compreende-se que a interdisciplinaridade não tem como objetivo descaracterizar a disciplina, mas que ela mostra como as disciplinas podem se completar a partir de um tema comum a todas.

\section{Abordagem interdisciplinar da Educação Ambiental}

Para Morin (2000, p. 37), a "[...] interdisciplinaridade controla tanto as disciplinas como a ONU controla as nações", pois cada uma demarca seu território, reafirmando as fronteiras, no entanto abrangem um bem comum.

Ao voltar ao conceito sobre o tema interdisciplinaridade na visão de outra autora, Tristão (2001), percebe-se que a EA é compreendida a partir de uma racionalidade técnica e instrumental, ou seja, ao preservar o meio ambiente, se resolve a situação, reproduzindo também os sentidos difundidos nos discursos oficiais das mídias (livros didáticos e televisão), baseados na Pedagogia da Declaração. Contudo, é válido ressaltar que os meios de comunicação podem até cumprir um papel instrutivo e formar opiniões, mas, em sua maioria, acabam sendo um instrumento político com uma abordagem ambiental extremamente pontual e imediatista.

Nota-se, por conseguinte, que o papel da EA é amplo, em que se procura articular diversas disciplinas. Este talvez seja o primeiro desafio a ser superado: fazer com que o conhecimento se processe por meio da interdisciplinaridade.

Com a EA sendo aplicada de forma interdisciplinar tem-se o desejo de agregar conhecimentos das ciências, resgatar conhecimentos populares, onde deve-se desestimular o consumismo, o uso exagerado do descartável, resgatar valores humanos e criar-se mentes sustentáveis. Neste contexto, Leff (2012, p. 31) diz que

[...] o saber ambiental não se integra às ciências, mas as impele a se reconstituir a partir do questionamento de uma racionalidade ambiental, e a se abrir para novas relações entre ciências e saberes, a estabelecer novas relações entre cultura e natureza e a gerar um diálogo de saberes, no contexto de uma ecologia política em que o que está em jogo é a apropriação social da natureza e a construção de um futuro sustentável. 
Percebe-se que as atividades educativas praticadas isoladamente não atingem os objetivos maiores da EA se dissociadas de um processo de planejamento contínuo de construção de conhecimentos.

\section{Metodologia}

Buscando fundamentar esta investigação, foi realizada uma pesquisa exploratória, que segundo Gil (2008) tem como propósito proporcionar maior familiaridade com o problema, com vistas a torná-lo mais explícito ou a construir hipóteses, procurando explorar e se familiarizar com a problemática em questão. Para isso, foi realizado um levantamento bibliográfico, além da produção e aplicação de questionários com os sujeitos da pesquisa, com o intuito de construir hipóteses para a análise da mesma.

A pesquisa bibliográfica foi estruturada a partir de vários estudos de referências de autores e leis que abordaram a temática em questão da EA. Deste modo, esta pesquisa configura um estudo de caso. E, de acordo com Gil (2008), os estudos de caso requerem a utilização de fontes documentais, questionários, entrevistas e observações.

Para a complementação desta pesquisa foi elaborado um questionário para ser aplicado para os docentes da escola em que a pesquisa foi realizada. O mesmo foi respondido tendo como amostra os 20 professores do Ensino Fundamental II que foram selecionados visando compreender as ações voltadas para a preservação da abordagem da prática da EA em sala de aula. Com base nesta investigação, houve a oportunidade de observar como são as aulas nas turmas, igualmente, verificar como a EA está sendo trabalhada na escola investigada.

A aplicação do questionário ocorreu durante o ano de 2019, dentro do universo da educação formal e do trabalho cotidiano dos educadores do Ensino Fundamental II de uma unidade da rede pública de forma interdisciplinar.

Os roteiros foram previamente estruturados, com perguntas abertas e fechadas, que procurou destacar os aspectos qualitativos possibilitando, assim, a obtenção de dados que proporcionaram uma análise da realidade da escola, e também conhecimento dos métodos trabalhados pelos docentes.

Por meio deste estudo de caso, objetivando apresentar um maior entendimento sobre a EA, foi escolhida uma escola localizada no sul do Estado do Espírito Santo, para a realização da coleta de dados a partir da problemática inicial. 


\section{Resultados e discussão}

Ponderando sobre a temática deste artigo, estão relacionados a seguir os dados que foram apontados ao longo da pesquisa sobre a escola polo que fica situada no sul do Estado do Espírito Santo.

Com isso, espera-se que todos tenham consciência dos problemas ambientais e se tornem agentes de mudanças que são fundamentais para que os gestos e as atitudes dos estudantes sejam voltados para a preservação do planeta.

Em relação aos professores do Ensino Fundamental II, todos os convidados responderam ao questionário de forma interdisciplinar por áreas específicas. Entre os 20 professores que responderam ao questionário, dois deles deixaram sem resposta a questão interdisciplinar. Um da área de Matemática e outro da área de Educação Física. Ambos se prontificaram a enviar as respostas pelo aplicativo de conversas WhatsApp, no entanto as mesmas não foram enviadas. Sendo assim, não houve contribuição por parte desses dois professores até o fim da tabulação desta pesquisa.

De acordo com a pesquisa realizada na escola municipal, os professores que responderam ao questionário afirmaram que a instituição dispõe de acesso à internet, e que nos anos anteriores cada professor efetivo ganhou um notebook. Os participantes também asseguraram que o ambiente escolar, além de possuir o acesso à internet, também disponibiliza uma sala multimídia, que é equipada com um aparelho data show para que os professores possam dinamizar as aulas deles e trabalhar de forma inovadora, enriquecendo o aprendizado dos alunos no dia a dia escolar.

$\mathrm{Na}$ Figura 1, os dados indicaram que 14 dos docentes responderam sim sobre terem formação acadêmica concluída, o que equivale a uma porcentagem de $78 \%$ dos educadores que participaram da pesquisa. Em seguida, os outros quatro profissionais restantes replicaram negativamente, 0 que corresponde a $22 \%$ dos respondentes. Esses dados só corroboram para reforçar a necessidade de atualização e de formação continuada para os educadores, conforme já citado anteriormente.

A partir desta etapa do questionário verificou-se o quantitativo de docentes e o tempo trabalhado na área de Educação, podendo-se, assim, analisar que três dos professores que responderam à questão, tem menos tempo atuando efetivamente na Educação. Isso demonstra uma margem percentual de $16,7 \%$ para o período máximo de até dez anos. Assim como, igualmente, com a mesma porcentagem de $16,7 \%$, estão os educadores que responderam que possuem menos de um ano de atuação efetiva na área educacional (Figura 2). 


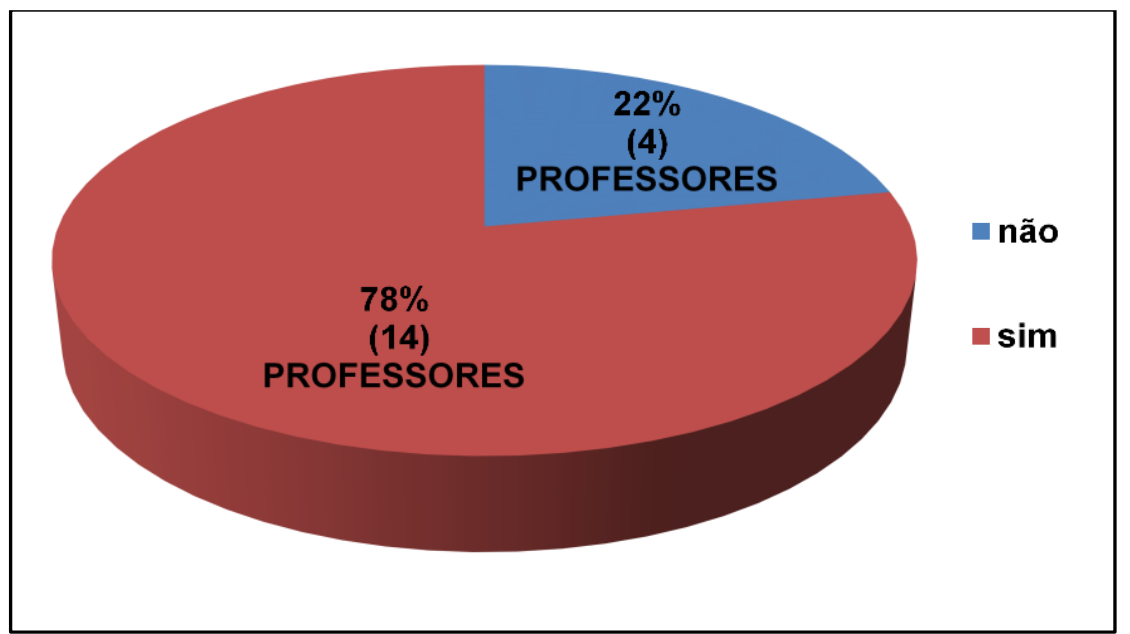

Figura 1: Percentual de profissionais que concluíram a formação acadêmica.

Fonte: Autoria própria.

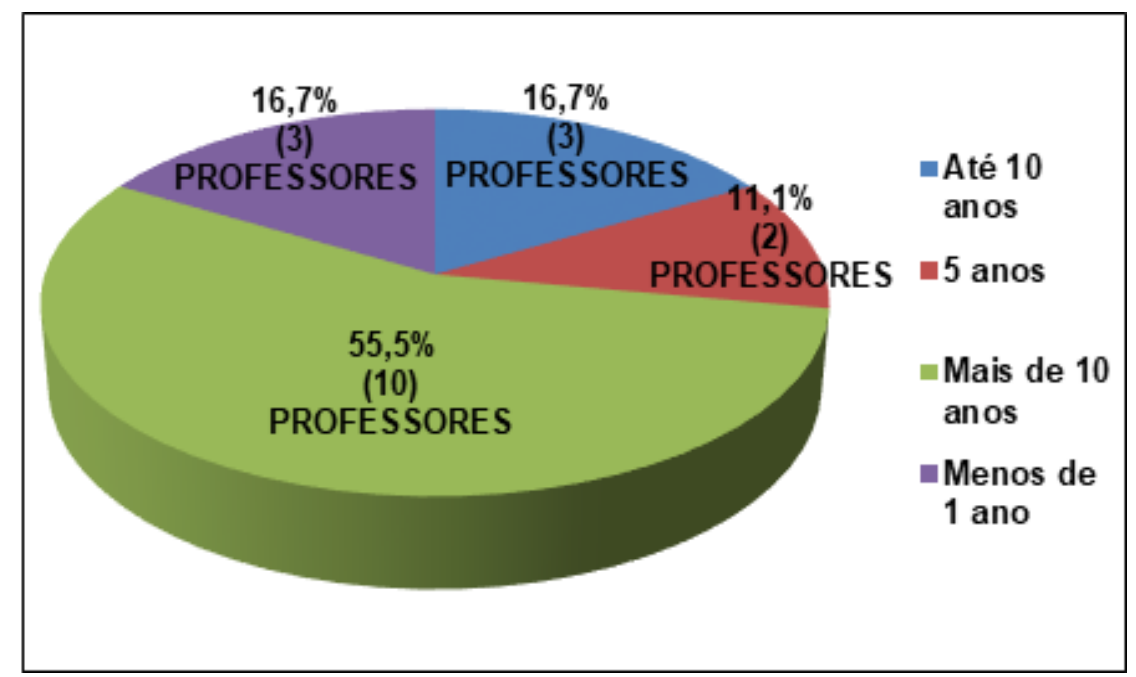

Figura 2: Período de trabalho na área da Educação.

Fonte: Autoria própria.

Observa-se que independente do tempo de serviço ou da experiência faz-se necessária a busca por capacitação. Inovar a cada dia a práxis de ensino é fundamental, pois o saber exige uma busca constante com afirma Freire (2007). Dessa forma, é preciso buscar conhecimento específico para enriquecer o nível de conhecimento na área da EA para proporcionar aos educandos aulas inovadoras, capazes de provocar reflexões, conforme elenca Brasil (1998).

Entre os outros educadores que também responderam à pesquisa, $11,1 \%$ replicaram que possuem cinco anos de prática no ramo educacional. Em seguida, percebeu-se, ainda, que a maioria dos docentes possuem uma carreira com mais de dez anos de atuação na Educação, o que corresponde sucessivamente a uma porcentagem de $55,5 \%$ dos participantes da pesquisa (Figura 2). 
De acordo com as informações da pesquisa realizada foi possível detectar, dessa maneira, como acontece a distribuição dos docentes, segundo a quantidade de turmas em que estes profissionais atuam, conforme demonstra o Quadro 2.

Quadro 2: Quantitativo de turmas em que os professores atuam

\begin{tabular}{|c|c|}
\hline Turmas & Professores \\
\hline $6^{\circ}$ Anos & 09 docentes \\
\hline $7^{\circ}$ Anos & 08 docentes \\
\hline $8^{\circ}$ Anos & 09 docentes \\
\hline $9^{\circ}$ Anos & 08 docentes \\
\hline
\end{tabular}

Fonte: Autoria própria.

Com base nos resultados desta pesquisa e no comparativo com os dados do Censo Escolar da Educação Básica realizado em 2017, em relação aos professores percebeu-se que no Ensino Fundamental II existem atualmente professores que trabalham atuando em mais de uma classe. Diante dessa perspectiva, evidenciou-se um fato relevante acerca das condições de trabalho dos educadores nos dias atuais que um estudo do MEC sobre o professor brasileiro mostra. O texto afirma que:

[...] A situação dos docentes dos anos finais, entretanto, difere daquela observada nos anos iniciais quanto ao número de turmas e de disciplinas ministradas, que são aspectos associados à forma de organização desta segunda fase do Ensino Fundamental, mas que servem também como indicadores das condições de trabalho desses profissionais (BRASIL, acesso em 17 out. 2019).

Sendo assim, tornou-se possível averiguar que um mesmo educador trabalha atuando mais de uma turma, lecionando a mesma matéria, o que confirmam os dados coletados e dispostos no Quadro 2. Na sequência, foi questionado aos participantes da pesquisa qual era o tempo que cada um deles tinha trabalhado na escola pesquisada (Quadro 3).

Quadro 3: Tempo de trabalho na escola pesquisada

\begin{tabular}{|c|c|}
\hline Período & Número de professores \\
\hline Menos de 1 ano & 8 docentes \\
\hline De 3 a 7 anos & 1 docente \\
\hline De 9 a 10 anos & 1 docente \\
\hline De 1 a 3 anos & 1 docente \\
\hline De 7 a 9 anos & 1 docente \\
\hline Mais de 10 anos & 6 docentes \\
\hline
\end{tabular}

Fonte: Autoria própria. 
Nesse caso, percebeu-se que os professores que têm mais tempo na área da Educação, com mais de dez anos de atuação, são seis docentes. Notou-se ainda que, geralmente, são os efetivos que tem a vaga garantida, isto é, que não precisam passar por um processo seletivo todos os anos para ver se conseguem uma vaga para trabalhar no ano seguinte.

Pôde-se verificar que os professores contratados com formação básica a cada ano trabalham em escolas diferentes. $E$, com isso, é gerada uma fragmentação no ensino sobre a temática EA, dificultando o trabalho contínuo de cada um em prol da aprendizagem.

Logo, torna-se difícil criar projetos que sejam permanentes e capazes de agregar a cada ano novas experiências do contexto da comunidade escolar, bem como da sociedade no geral.

Os docentes que responderam positivamente somam $67 \%$ dos entrevistados (Figura 3), e também acrescentaram à resposta que a EA é um tema amplo, um assunto que deve ser trabalhado de forma interdisciplinar - em que todas as disciplinas possam orientar os discentes sobre a importância do respeito ao meio ambiente e os problemas relacionados a ele como, por exemplo, a produção e o descarte do lixo. E isso considerando tanto o lixo doméstico quanto 0 industrial. Os educadores entrevistados acrescentaram ainda que esta formação de consciência deve ser levada para fora do âmbito escolar, por intermédio dos próprios estudantes.

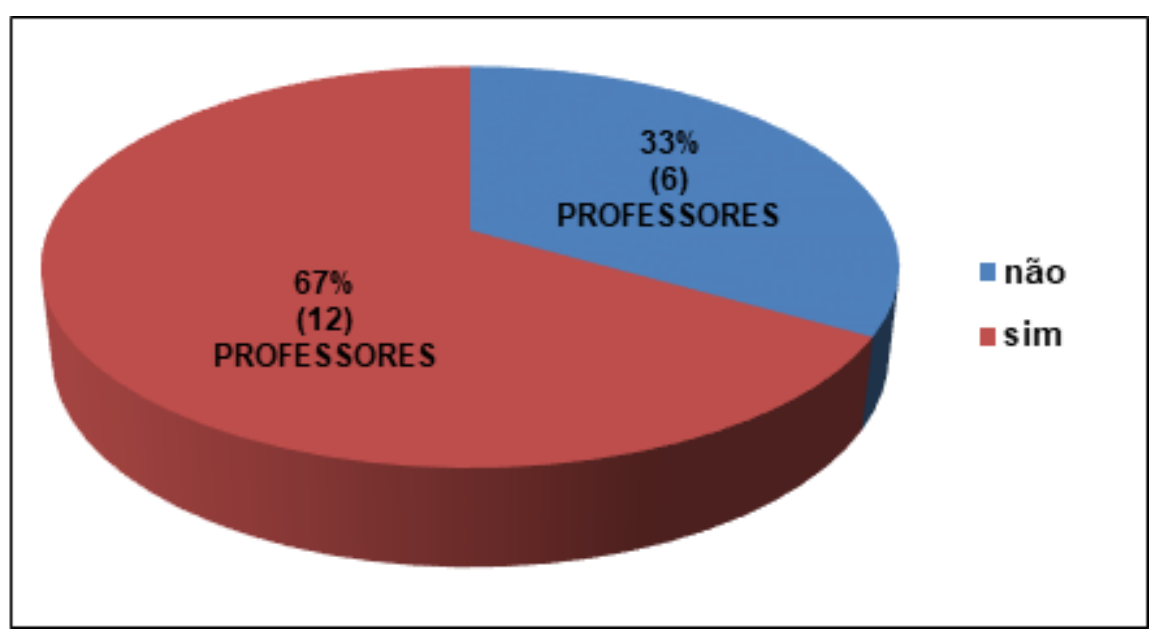

Figura 3: Compreensão sobre o que é Educação Ambiental.

Fonte: Autoria própria.

Já os docentes que responderam negativamente, que somam $33 \%$ dos respondentes, observaram a falta de formação dos profissionais da Educação em relação ao tema EA, para que possam passar esse conhecimento de forma adequada aos discentes. Os participantes comentaram que o problema 
ambiental não é pontual, por isso, deve e precisa ser trabalhado com toda a sociedade, em diversos níveis.

Nesse sentido, o capítulo II da Política Nacional de Educação Ambiental, no que refere à Educação Formal, reza em seu Parágrafo Único que:

Os professores em atividade devem receber formação complementar em suas áreas de atuação, com o propósito de atender adequadamente ao cumprimento dos princípios e objetivos da Política Nacional de Educação Ambiental (BRASIL, acesso em 16 out. 2019).

Assim, tornou-se possível concluir que EA engloba vários pensamentos e definições, bem como também pôde-se notar que o docente não procura realmente se qualificar ou capacitar. Como alguns dos entrevistados indicaram, a maioria desses educadores acaba deixando esse assunto por responsabilidade única e exclusiva dos órgãos educacionais.

Ao serem questionados sobre as principais atividades de EA que são desenvolvidas pela escola, foi solicitado que os entrevistados indicassem a ordem de relevância de cada uma delas, sendo 1 para a de maior e 2 para a de menor importância (Quadro 4).

Quadro 4: Principais atividades de Educação Ambiental desenvolvidas pela escola

\begin{tabular}{|l|c|c|}
\hline \multicolumn{1}{|c|}{ OPÇÕES } & $\begin{array}{c}\text { MAIOR } \\
\text { IMPORTÂNCIA (1) }\end{array}$ & $\begin{array}{c}\text { MENOR } \\
\text { IMPORTÂNCIA (2) }\end{array}$ \\
\hline Mobilização & $55,5 \%$ & $44,4 \%$ \\
\hline Sensibilização & $72,3 \%$ & $27,7 \%$ \\
\hline Produção de material pedagógico & $66,6 \%$ & $33,4 \%$ \\
\hline OUTRAS OPÇÕES & $5,5 \%$ \\
\hline Participação de programas externos & $5,5 \%$ \\
\hline Reciclagem & $5,5 \%$ \\
\hline Pôr em prática todo o projeto &
\end{tabular}

Fonte: Autoria própria.

Os dados coletados demonstraram que na opção de sugestões os docentes apontaram outras opções possíveis de atividades de EA desenvolvidas pela escola. Três (3) deles deram as seguintes opções: a) participação de programas externos - um (1) docente deu essa resposta, o que corresponde a $5,5 \%$; b) reciclagem - um (1) docente elegeu com um percentual de 5,5\%; e o terceiro docente optou pela opção c) pôr em pratica todo o projeto, o que também corresponde a uma porcentagem de $5,5 \%$.

Diante desse cenário, no comprometimento do docente com a EA vêse a necessidade e o objetivo de resgatar no aluno os valores de comportamento, respeito, solidariedade e atenção aos fatos do dia a dia que afetam o meio ambiente - o meio em que se vive. $E$ todas as disciplinas são 
importantes. Por isso, a interdisciplinaridade pode ser visualizada como uma teia em que cada ponto que é tecido é vital. E, sobre essa relação, Tristão (2004, p. 25) acredita que

A Educação Ambiental, na sua complexidade, configura-se como possibilidade de religar a natureza, o sujeito e o objeto, enfim. Entretanto, baseada na relação do ser humano com o meio ambiente, da sociedade com a natureza, das sociedades entre si, encontra-se em construção e em debate.

Perante o panorama revelado pelos dados da pesquisa, é válido ressaltar a importância de se refletir e procurar qualificar-se para que se possa participar dos problemas ambientais, avaliando soluções e ações que podem fazer a diferença.

Como resultado final da pesquisa sugeriu-se a capacitação dos educadores com uma formação continuada por meio de oficinas com artesanato e reciclagem para professores do Ensino Fundamental II da escola em que foi realizada a pesquisa.

Por meio das oficinas focadas em reciclagem e artesanato, os professores podem envolver os alunos e a comunidade local, reciclar o próprio material que é descartado na escola, estimular a reciclagem em casa, exibir e assistir vídeos junto com os alunos, ensinar e aprender por meio de outros projetos, além de usar a criatividade expressada no artesanato.

Espera-se que no decorrer do projeto haja uma interação entre professor, aluno, família e comunidade, em que novas ideias possam surgir para agregar e aperfeiçoar cada etapa do projeto. Além disso, existe a possível geração de renda para as famílias com os produtos gerados pelo projeto.

\section{Conclusões}

Os dados e as informações que foram coletados ao longo desta pesquisa permitiram perceber que os projetos precisam incorporar efetivamente o âmbito escolar, ter um olhar crítico e analisar os avanços do processo histórico da EA. Com isso, deve-se buscar trabalhar o meio ambiente em sua complexidade, analisando as causas reais dos problemas ambientais e procurar efetivar a integração de forma interdisciplinar.

Para isso, o professor necessita de uma carga horária mais flexível que possibilite ao docente o desenvolvimento das atividades extracurriculares. Os materiais pedagógicos também são um fator importante nesta questão, pois, estão aquém do mínimo necessário.

Assim sendo, notou-se que muito ainda há de ser feito com relação a EA, pois percebeu-se que as ações tomadas pelos organismos responsáveis, 
se distanciam de uma perspectiva de EA crítica, problematizadora, politizada, questionadora, integrada aos interesses das populações e das classes sociais mais afetadas, e que permita uma real percepção das causas socioambientais.

De acordo com os resultados do questionário aplicado aos educadores em uma escola municipal do sul do Estado do Espírito Santo, observou-se que os professores do Ensino Fundamental II têm dificuldades em trabalhar a interdisciplinaridade.

A EA mostra-se, cada dia mais, como uma necessidade da sociedade, e também de atualização do aprendizado, pois nota-se que os projetos que foram implementados no passado precisam ser atualizados e adaptados - os problemas mudaram e outros já surgiram e foram acrescentados posteriormente. Isso sem contar os que ainda irão surgir para as próximas gerações.

Portanto, a discussão e as ações práticas desse assunto representam uma medida importante e fundamental para a inserção da EA na formação e na didática do professor.

Para finalizar, conclui-se que a EA é, sem dúvida, um tema amplo no qual há necessidade de interação entre as disciplinas. Todavia, é fundamental que haja não só a capacitação neste sentido, mas, igualmente, o interesse do profissional de Educação em transmitir o aprendizado.

\section{Referências}

AGENDA 21. Conferência Nacional das Nações Unidas sobre o meio ambiente e desenvolvimento (1992: Rio de Janeiro). Curitiba: IPARDES, 2001. 260p.

BRASIL. Constituição (1988). Constituição da República Federativa do Brasil. Brasília, DF: Senado Federal: Centro Gráfico, 1988.

BRASIL. Decreto no 4.281, de 25 de junho de 2002: Regulamenta a Lei no 9.795, de 27 de abril de 1999, que institui a Política Nacional de Educação Ambiental, e dá outras providências. Diário Oficial da República Federativa do Brasil, v. 139, n. 121, 2002.

BRASIL. Ministério da Educação. Parâmetros Curriculares Nacionais. Ministério da Educação e do Desporto / Secretaria de Educação Fundamental. Brasília: MEC, 1997.

BRASIL. Ministério do Meio Ambiente (MMA). Agenda 21 Global. Documento Agenda 21 da Conferência das Nações Unidas sobre Meio Ambiente e Desenvolvimento. Disponível em: <https://www.mma.gov.br/responsabilidadesocioambiental/agenda-21/agenda-21-global>. Acesso em: 12 ago. 2019.

DIAS, G.F. Educação Ambiental: princípios e práticas. São Paulo, Gaia, 1992. 
DIAS. G.F. Educação Ambiental: princípios e práticas. 8.ed. São Paulo: Gaia, 2003. 551p.

FREIRE, P. Pedagogia do Oprimido. Rio de Janeiro: Paz e Terra, 1987.

FREIRE, P. Educação e mudança. Rio de Janeiro: Paz e Terra. p. 64. 2007.

GIL, A.C. Métodos e técnicas de pesquisa social. 6. ed. São Paulo: Atlas,2008.

GUIMARÃES, M. A dimensão ambiental na educação. Campinas-SP: Papirus, 2007.

HAMMES, V.S. Construção da proposta pedagógica. 3 ed. Rev. e Ampl. Brasília, DF: Embrapa, 2012.

LEFF, E.Z. Complexidade, racionalidade ambiental e diálogo de saberes educação \& realidade, vol. 34, núm. 3, 2009, pp. 17-43.

LEFF, E.Z. Aventuras da epistemologia ambiental: da articulação das ciências ao diálogo de saberes; tradução de Silvana Cobucci Leite. São Paulo: Cortez Editora, 2012.

MORIN, E. O problema epistemológico da complexidade. Portugal: Publicações Europa-América, 1996.2. ed. 2000.

PPP, Projeto Político Pedagógico. Escola Municipal de Educação Infantil e Ensino Fundamental (EMEIEF) de Jaqueira "Bery Barreto de Araújo". Presidente Kennedy. Espírito Santo. 2019.

REIGOTA, M. O que é Educação Ambiental? 2. ed. São Paulo: Brasiliense, 2009.

STEIN, D.S.; DOROW, T.S.C. Ações educativas ambientais no cotidiano de uma escola municipal de Santa Maria - RS. Revista Monografias Ambientais, [S.I.], v. 4, n. 4, p. 596-606, out. 2011.

TRAJBER, R.; SATO, M. Escolas Sustentáveis: Incubadoras de Transformações nas Comunidades. Rev. Eletrônica Mestr. Educ. Ambient. ISSN 1517-1256, v. especial; 2010 Nov [cited 2013 nov 7].

TRISTÃO, M. "A escola é o meio ambiente", afirma Martha Tristão. Luciana Maximo. Destaques. Especial. 03/03/2016. Disponível em: $<$ https://www.espiritosantonoticias.com.br/a-escola-e-o-meio-ambiente-afirmamartha-tristao/>. Acesso em: 10 ago. 2019.

VEIGA, A.; AMORIM, E.; BLANCO, M. Um retrato da presença da Educação Ambiental no Ensino Fundamental Brasileiro: o percurso de um processo acelerado de expansão. Brasília: Instituto Nacional de Estudos e Pesquisas Educacionais Anísio Teixeira, 2005. 